\title{
Implementasi Location Based Service Pada Aplikasi Mobile Pencarian Halte BRT Transmusi Palembang
}

\author{
Usman Ependi ${ }^{1)}$, Suyanto ${ }^{2)}$ \\ ${ }^{1,2)}$ Program Studi Informatika, Fakultas Ilmu Komputer, Universitas Bina Darma \\ Jl Ahmad Yani No 3 Plaju, Palembang \\ ${ }^{1)}$ u.ependi@binadarma.ac.id \\ ${ }^{2)}$ suyanto@binadarma.ac.id
}

\begin{abstract}
Abstrak-BRT Transmusi Palembang, merupakan sarana angkutan umum masyarakat kota palembang yang sedang berkembang dengan pesat. Sampai saat ini armadanya sudah mencapai 180 unit dan didukung dengan keberadaan halte yang jumlahnya mencapai 290 halte. Untuk menggunakan jasa BRT TransMusi, masyarakat terlebih dahulu harus menuju ke halte terdekat. Banyaknya halte yang tersebar di penjuru kota Palembang, justru menyebabkan kebingungan bagi pengguna untuk menentukan halte mana yang harus dia tuju. Untuk itu, masyarakat perlu panduan agar bisa menemukan dan menuju halte dengan cepat. Penelitian ini mengembangkan aplikasi mobile pencarian halte BRT TransMusi berbasis lokasi. Dengan aplikasi ini pengguna dapat dengan mudah menemukan dan menuju halte terdekat dari posisinya berada karena aplikasi ini akan menampilkan peta jalan untuk menuju ke lokasi halte terdekat. Aplikasi ini dikembangkan dalam bentuk mobile, karena pengguna akan lebih mudah dan lebih cepat dalam mengakses aplikasi ini. Selain itu dengan perangkat mobile pengguna bisa mengakases aplikasi ini kapan saja dan dimana saja dalam wilayah kota Palembang.
\end{abstract}

Kata Kunci- Halte, transmusi, mobile, location base service

Abstract- BRT Transmusi Palembang, a public transportation city of Palembang society that is growing rapidly. To date the fleet has reached 180 units and is supported by the presence of the stop number reached 290 stops. To use TransMusi BRT services, people must first go to the nearest bus stop. The number of bus stops are scattered throughout the city of Palembang, it causes confusion for users to determine which one should stop him going. For that, people need to be able to find a guide to the bus stop and quickly. This study developed a mobile application search BRT TransMusi stop location-based. With this application, users can easily find and headed to the nearest stop of the position is because the application will display a map of the road to get to the nearest bus stop locations. The application was developed in the form of mobile, because users will be easier and faster to access this application. In addition to mobile device users can access the application anytime and anywhere within the city of Palembang.

Keywords- Halte, transmusi, mobile, location base service

Article History:

Received 03 March 2016; Received in revised form 8 April 2016; Accepted 14 April 2016; Availaible online 30 April 2016

\section{PENDAHULUAN}

Pemanfaatan teknologi Location Base Service pada aplikasi-aplikasi mobile dan smartphone semakin banyak digunakan. Hal ini dilatarbelakangi dengan semakin meningkatkan kegiatan masyarakat terutama kalangan eksekutif dalam urusan bisnis maupun urusan travelling. Terbatasnya pengetahuan seseorang tentang daerah yang dituju, menjadi kendala tersendiri bagi para pelancong ataupun para eksekutif yang sedang melakukan perjalanannya ke suatu daerah. Dengan demikian perlu adanya pemandu yang bisa menuntun dan menunjukkan posisi dimana saat ini seseorang itu berada. Dengan menggunakan teknologi Location Base Service, hal ini bisa diwujudkan dengan baik. Teknologi ini disematkan dalam bentuk aplikasi yang mudah dijangkau dan dioperasikan oleh pengguna, yaitu dalam bentuk aplikasi yang berjalan pada gadget atau smartphone yang sudah banyak digunakan orang. Dengan adanya aplikasi ini, maka seseorang yang sedang mengadakan perjalanan ke tempat yang belum dikenalnya sama sekali tidak perlu khawatir akan tersesat. Dengan teknologi ini kita bisa mencari dan menuju suatu tempat cukup dengan mengikuti peta jalan yang bisa diakses setiap saat dari gadget maupun smartphone yang kita punya.

Penelitian-penelitian yang serupa telah dikembangkan oleh kalangan akademisi, antara lain : Aplikasi Location Based Service Pencarian Tempat Di Kota Manado Berbasis Android yang dikembangkan oleh (Rompas, Sinsuw, Sompie, \& Lumenta, 2012). Permasalahan utama pada penelitian ini adalah kesulitan seseorang mengetahui posisi atau lokasi dia saat ini serta kesulitan mencari lokasi suatu tempat yang ingin dituju. Pada penelitian ini menghasilkan suatu aplikasi mobile yang dapat mengetahui dan menampilkan posisi user dengan tempat-tempat tertentu. Aplikasi ini terintegrasi dengan layanan 
GoogleMap dalam penentuan jalur ke tempattempat yang ingin dituju.

Penelitian lain telah dilakukan oleh (Aljufri, 2012). Penelitian yang dikembangkan berjudul Sistem Pemandu Pencarian Masjid Terdekat Berbasis Lokasi di atas Platform Android. Masalah yang ingin diselesaikan pada penelitian ini pencarian lokasi masjid yang terdekat dengan posisi user saat ini. Masalah ini banyak dialami oleh user terutama saat bepergian ke suatu tempat yang masih baru. Penelitian ini menggunakan IDE Eclipse dan Google API dalam pengembangannya. Dalam pencarian posisi pengguna, aplikasi ini memanfaatkan Global Positioning System (GPS). Map dan Driving Route merupakan fasilitas utama yang diterapkan dengan bantuan Google Maps API.

Dari penelitian yang dilakukan (Rompas, Sinsuw, Sompie, \& Lumenta, 2012), terlihat bahwa penelitian yang dilakukan masih bersifat lokal, yaitu hanya bisa digunakan di daerah Manado saja. Sedangkan penelitian yang dilakukan oleh Aljufri, mungkin bisa digunakan disemua tempat tetapi terbatas hanya untuk pencarian masjid saja. Dan penelitian yang penulis kembang saat ini adalah bersifat lokal untuk masyarakat kota Palembang atau pendatang yang sedang berada di kota Palembang.

Kota Palembang merupakan kota yang mempunyai perkembangan yang tak kalah cepatnya dengan kota-kota besar lain di Indonesia. Salah satunya adalah terwujudnya sarana angkutan umum yang sangat memadai bagi masyarakat kota Palembang. Angkutan yang dimaksud adalah Bus Rapid Transit TransMusi (BRT TransMusi) Palembang. BRT TransMusi ini dikelola oleh PT. Sarana Pembangunan Palembang Jaya (PT. SP2J) yang merupakan Badan Usaha Milik Daerah Kota Palembang. BRT TransMusi Palembang melakukan soft opening pada tanggal 22 Februari 2010, yang dibuka langsung oleh Walikota Palembang saat itu Ir. Eddy Santana Putra, MT. Jumlah armada BRT TransMusi hingga tahun 2012 berjumlah 120 unit armada dan di tahun 2013 akan ditambah 60 unit armada lagi sehingga mencapai 180 unit armada. Jumlah ini akan terus bertambah hingga mencapai 275 unit armada. Hal ini dilakukan untuk menjaga agar jarak antar armada hanya membutuhkan waktu 10 menit saja. Dengan banyaknya jumlah armada tersebut, maka diperlukan sebuah aplikasi yang mampu memberikan informasi tentang keberadaan armada BRT TransMusi tersebut secara cepat dengan menggunakan perangkat mobile.

Dengan keberadaan BRT TransMusi ini, masyarakat kota Palembang sangat antusias dalam memanfaatkan angkutan ini. Hal ini dikarenakan berbagai keuntungan yang bisa diperoleh dari menggunakan BRT Transmusi ini, diantaranya: keamanan, kenyamanan dan ketepatan waktu. Bus
BRT Transmusi sangat aman karena pintu buka/tutup hanya bisa dilakukan oleh pengemudi, dan nyaman karena semua BRT TransMusi dilengkapi dengan pendingin udara sehingga pengguna tidak kepanasan selama menggunakan jasa angkutan ini. Untuk menjamin kepastian layanan kepada pengguna, operasional BRT TransMusi diatur sedemikian rupa dengan jam keberangkatan yang selalu tepat waktu setiap 1015 menit sekali di setiap terminal keberangkatan maupun di halte-halte yang telah disediakan. Dengan kata lain, bus tidak pernah ngetem sehingga perjalanan lebih singkat. Dengan kondisi yang demikian maka Load factor Transmusi pun sangat tinggi yaitu mencapai $75 \%$, dengan jumlah penumpang 7.500 orang/hari dan rata-rata jumlah pengguna tiap bulannya sebesar 225.000 orang. Begitu banyaknya masyarakat pengguna BRT TransMusi di Palembang, maka sudah sewajarnya apabila mereka mempunyai aplikasi yang mudah diakses melalui perangkat mobile untuk memberikan informasi yang berhubungan dengan keberadaan BRT TransMusi.

Sarana pendukung lainnya yang dimiliki oleh BRT TransMusi dalam melayani masyarakat kota Palembang adalah tersedianya sejumlah halte yang tersebar di banyak titik di kota Palembang. Haltehalte tersebut dibangun menggunakan APBD Kota Palembang dan beberapa dibangun oleh pihak ketiga, yaitu BUMN, swasta dan perguruan tinggi. Kebutuhan akan halte secara ideal adalah sebanyak 400 halte, namun yang tersedia saat ini baru 290 halte. Ini berarti masih terjadi kekurangan sebanyak 110 halte lagi yang perlu dibangun untuk melayani masyarakat kota Palembang. Banyaknya halte-halte yang tersebar di penjuru kota Palembang, ternyata menimbulkan permasalahan tersendiri bagi masyarakat. Masyarakat sering mengalami kesulitan dalam mencari dan menentukan halte mana yang harus dia tuju agar mendapatkan BRT Transmusi yang sesuai dengan tujuan mereka, terlebih lagi bagi masyarakat pendatang. Oleh karena itu diperlukan pengembangan aplikasi yang bisa dijadikan sebagai petunjuk halte mana yang terdekat dari posisi dia saat ini atau halte mana yang harus dituju untuk pergi ke suatu tempat di kota Palembang. Tentunya aplikasi yang akan dibangun tersebut adalah aplikasi yang mudah diakses dimana saja dan kapan saja oleh masyarakat. Aplikasi yang tepat adalah aplikasi yang berbasiskan mobile, mengingat perangkat mobile (Smartphone) sekarang ini sudah banyak digunakan oleh masyarakat.

Dalam pengembangan aplikasi mobile ini akan menggunakan metode pengembangan Evolutionary Development. Metode ini berdasarkan pada ide untuk mengembangkan implementasi awal, memperlihatkannya pada user untuk dikomentari, lalu memperbaikinya versi 


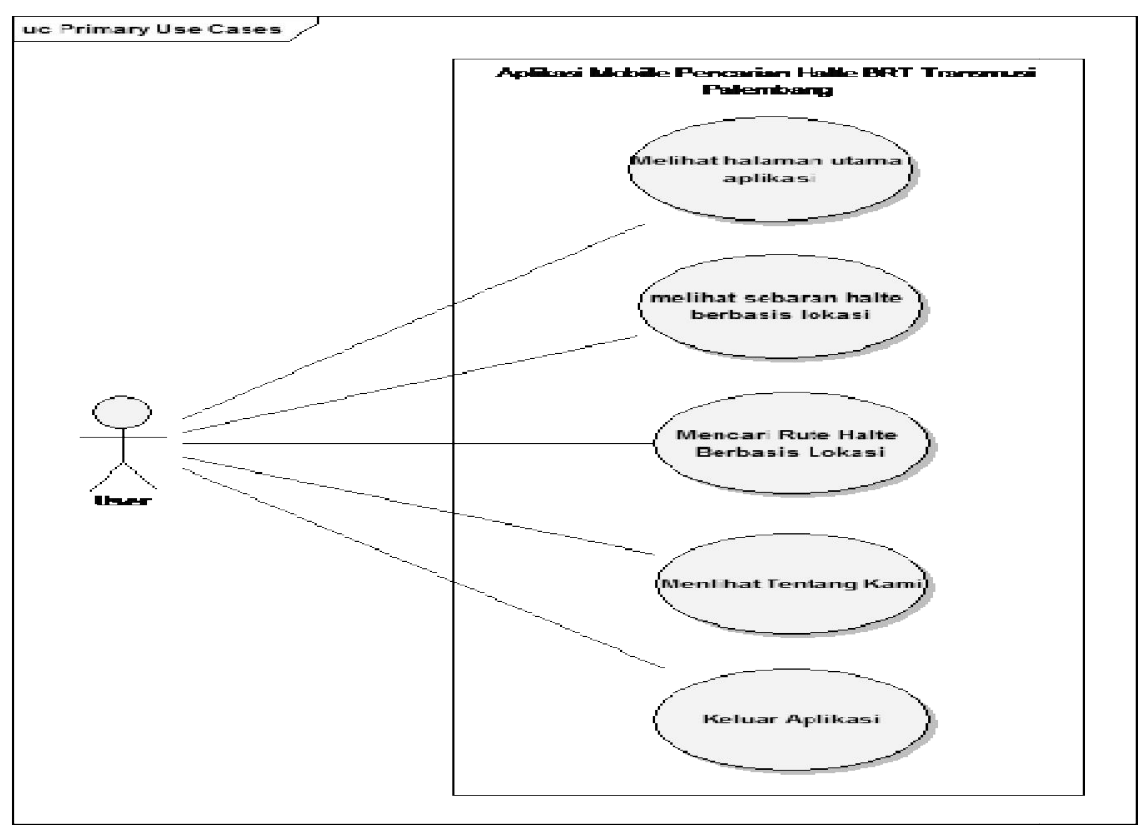

Gambar 1. Use Case Diagram

demi versi. Tidak ada kegiatan spesifikasi, validasi, dan pengembangan yang terpisah. Dalam metode ini ada dua jenis pendekatan yaitu : pengembangan eksploratori (bekerja dengan pelanggan untuk menyelidiki kebutuhan pelanggan dengan mengirimkan sistem akhir) dan prototype yang dapat dibuang (throw-away / eksperimen dengan kebutuhan pelanggan yang tidak dipahami dengan baik). Permasalahan yang diselesaikan dalam penelitian ini adalah mengimplementasikan Metode Location Base Service (LBS) dalam membangun aplikasi mobile pencarian halte BRT TransMusi Palembang berbasis lokasi.

\section{Metodologi Penelitian}

Dalam melakukan penelitian ini terdapat metode-metode yang digunakan sebagai langkah penyelesaian penelitian. Untuk itu berikut ini dapat dilihat metode-metode tersebut.

Metode penelitian yang digunakan dalam penelitian ini adalah metode deskriptif. Dimana penelitian deskriptif adalah suatu bentuk penelitian yang ditujukan untuk mendeskripsikan fenomenafenomena yang ada, baik fenomena alamiah maupun fenomena buatan manusia. Fenomena itu berupa bentuk, aktivitas, karakteristik, perubahan, hubungan, kesamaan, dan perbedaan antara fenomena yang satu dengan fenomena lainnya (Sukmadinata, 2006).

Teknik pengumpulan data sesuai dalam (Umar, 2003) yaitu :

1. Pengamatan (Observasi) adalah pengumpulan data dengan cara melakukan pengamatan langsung kepada objek penelitian yaitu ke halte-halte di kota Palembang.
2. Wawancara langsung maupun tidak langsung kepada sumber-sumber data.

3. Dokumentasi adalah pengumpulan data melalui dokumen-dokumen dan laporanlaporan yang ada di perusahaan yang memiliki relevansi dengan penelitian.

Metode pengembangan sistem yang akan digunakan dalam penelitian ini adalah metode Evolutionary Development (Pressman, 2010) (Sommerville, 2011). Terdapat 2 macam pendekatan :

1. Exploratory development (Pengembangan dengan penyelidikan)

Bertujuan untuk bekerja sama dengan klien untuk membangun sebuah sistem dari spesifikasi awal. Harus dimulai dengan pemahaman kebutuhan yang memadai.

2. Throw-away prototyping

Bertujuan untuk mengerti akan kebutuhan sistem. Dimulai dengan pemahanan kebutuhan yang sangat minim, karena pada umumnya konsumen mendefinisikan sekumpulan tujuan secara umum untuk software, tetapi tidak mengidentifikasikan secara detail mengenai input, proses dan output yang diperlukan

\section{HASIL DAN PEMBAHASAN}

Hasil dan pembahasan dalam melakukan implementasi location based service pada aplikasi mobile pencarian halte BRT transmusi Palembang 


\section{A. Hasil}

Penelitian yang dilakukan berdsarkan fase yang ada pada Evolutionary Development dapat dijelaskan sebagai berikut:

\section{1) Diskripsi Awal}

Pada tahapan ini peneliti melakukan pendeskripsian semua kebutuhan yang akan dimasukkan dalam aplikasi. Dimana dalam proses ini dibuat kesepaatan dengan pengguna akhir aplikasi. Dalam fase ini juga dibuat hasil analisis yang dapat dilihat dari use case diagram pada Gambar 1.

\section{2) Diskripsi Sistem yang Berjalan}

Pada tahapan deskripsi sistem yang berjalan pekerjaan yang dilakukan antara lain adalah sebagai berikut:

a) Spesifikasi

Pada tahapan spesifikasi peneliti merumuskan bentuk dan kebutuhan aplikasi yang akan dikembangkan. Dimana pada tahapan ini menghasilkan versi awal dari aplikasi mobile pencarian halte BRT Transmusi Palembang. Dimana dalam spesifikasi ini versi awal yang di hasilkan antara lain class diagram, activity diagram, sequence diagram dan perancangan antar muka. Pada Gambar 2 dan Gambar 3 berikut ini dapat dilihat hasil initial version dari aplikasi mobile pencarian halte BRT Transmusi Palembang.

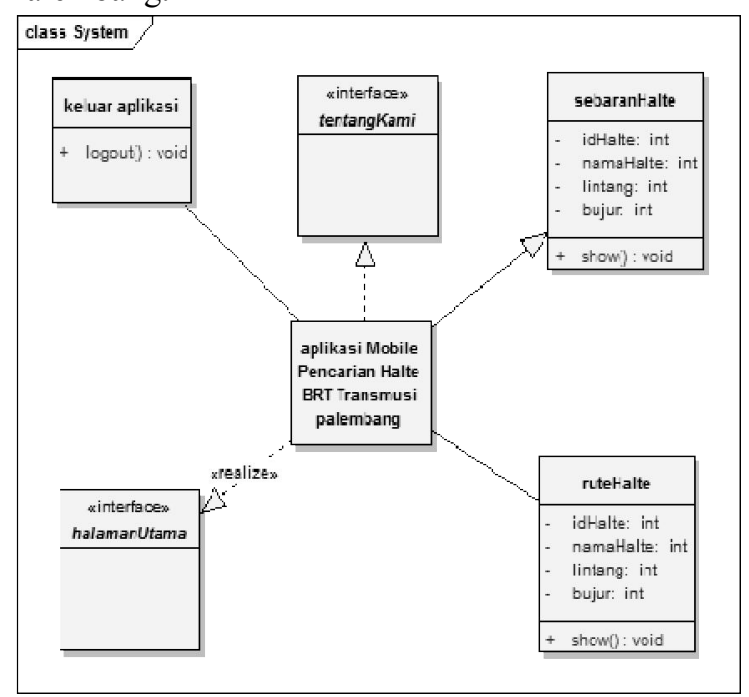

Gambar 2. Class Diagram

Dapat dilihat pada Gambar 2 class diagram diatas adalah untuk melihat struktur statis dan hubungannya secara logika dari aplikasi mobile pencarian Halte BRT Transmusi Palembang. Class Diagram ini dibentuk berdasarkan hasil analisis atau fase outline. Dari gambar diatas dapat dilihat ada 5 kelas yang dihasilkan, yaitu: kelas halaman utama, kelas rute halte, kelas sebaran halte, kelas tentang kami, dan kelas keluar aplikasi. Kelima kelas tersebut berhubungan satu dengan yang lain dan membentuk sebuah aplikasi. Sedangkan untuk mengetahui aktifitas dari pengguna dalam Aplikasi Mobile Pencarian Halte BRT Transmusi Palembang ini maka dapat dilihat pada activity diagram yang terlihat pada Gambar 3 berikut ini.

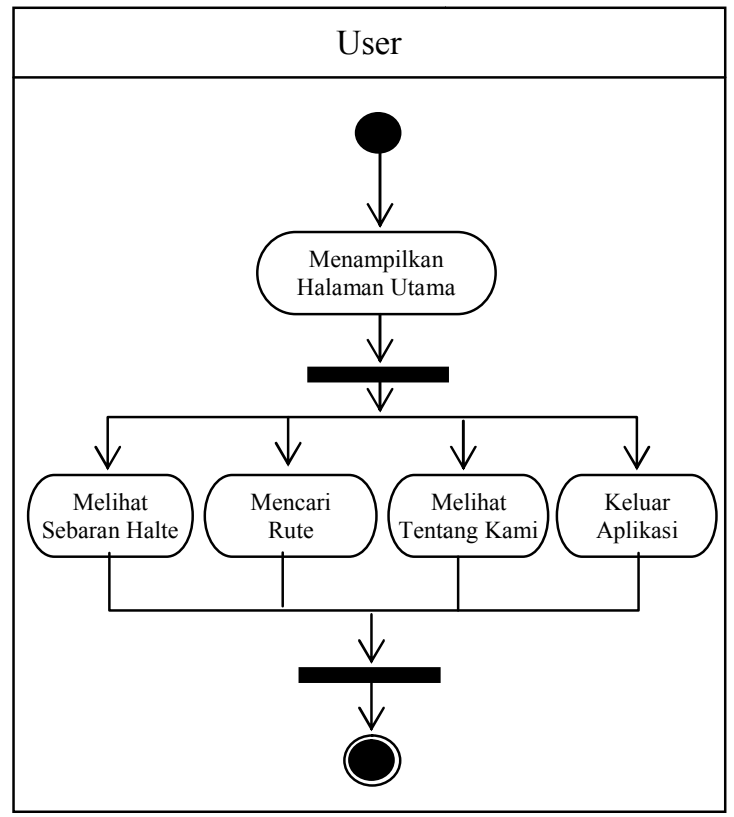

Gambar 3. Activity Diagram

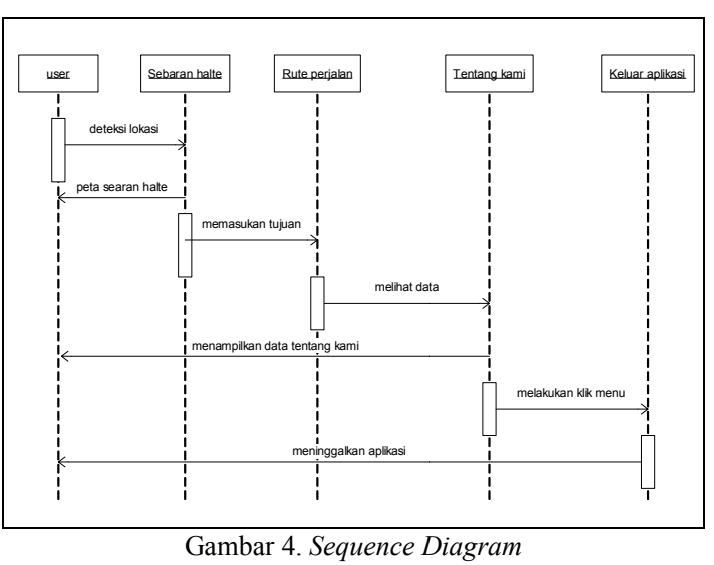

Untuk memodelkan jalur kerja, memodelkan aktifitas aktor, bagaimana objek-objek bekerja, aksi-aksi dan pengaruh terhadap objek maka dapat digambarkan melalui sequence diagram. Sequence diagram Aplikasi Mobile Pencarian Halte BRT Transmusi Palembang terlihat pada Gambar 4. Pada sequence diagram yang terlihat pada Gambar 4 adalah sequence yang dilihat dari sisi pengguna atau user pemakai Aplikasi Mobile Pencarian Halte BRT Transmusi Palembang

Dari class diagram, activity diagram dan sequence diagram pada Gambar 2-4, dapat dibentuk perancangan antarmuka pembentuk aplikasi mobile pencarian halte BRT Transmusi Palembang. Antarmuka pertama yang dapat dilihat yaitu rancangan halaman utama aplikasi seperti yang terlihat pada Gambar 5. 


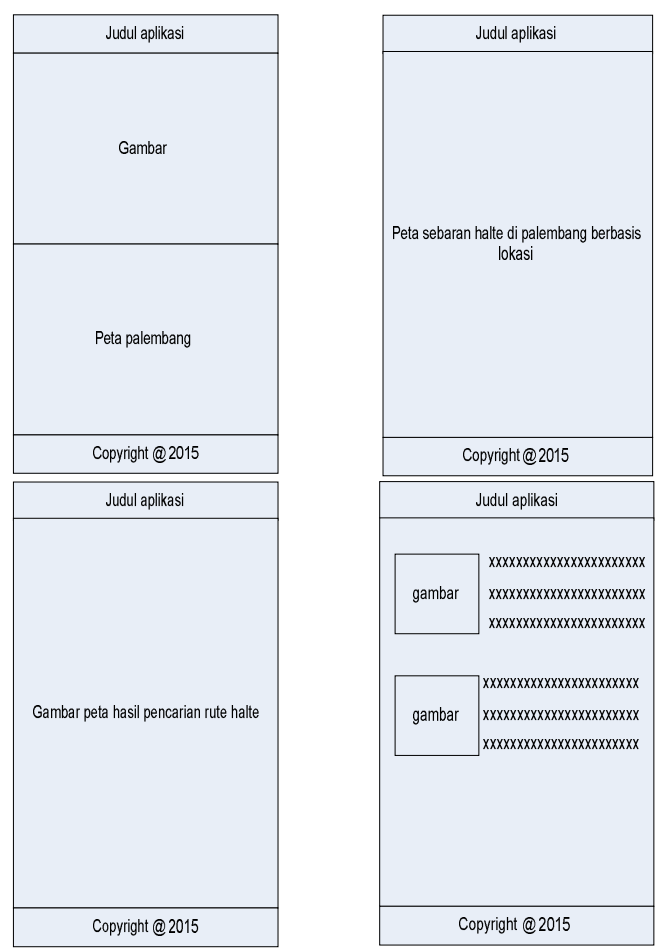

Gambar 5. Perancangan Halaman. Terdiri atas halaman utama, halaman peta sebaran halde, halaman pencarian rute, dan halaman tentang kami.

Terdapat 4 rancangan halaman, yaitu halaman utama, halaman sebaran halte, halaman rute berbasis lokasi dan halaman tentang kami

Dari perancangan halaman utama ini dapat melakukan akses ke halaman-halaman lain yaitu halaman sebaran halte, halaman rute berbasis lokasi dan halaman tentang kami. Rancangan sebaran halte adalah rancangan halaman yang nantinya akan menampilkan sebaran letak halte transmusi yang ada di kota Palembang. Halaman pencarian halte digunakan untuk mencari halte tujuan berdasarkan lokasi pengguna aplikasi mobile pencarian halte BRT transmusi Palembang. Sedangkan perancangan halaman tentang kami adalah perancangan halaman untuk menampilkan informasi pembuat aplikasi mobile pencarian halte BRT Transmusi Palembang.

\section{b) Development}

Tahapan development adalah tahapan pengembangan aplikasi mobile pencarian halte BRT Transmusi Palembang. Dimana pada fase ini pengembangan yang dilakukan menggunakan android dengan tools eclips. Pengkodean yang dilakukan antara lain adalah pembentukan halaman utama aplikasi, halaman sebaran halte, halaman pencarian rute perjalanan, halaman info dan halaman tentang kami. Berikut ini adalah tampilan code dari manifes aplikasi mobile pencarian halte BRT Transmusi Palembang.

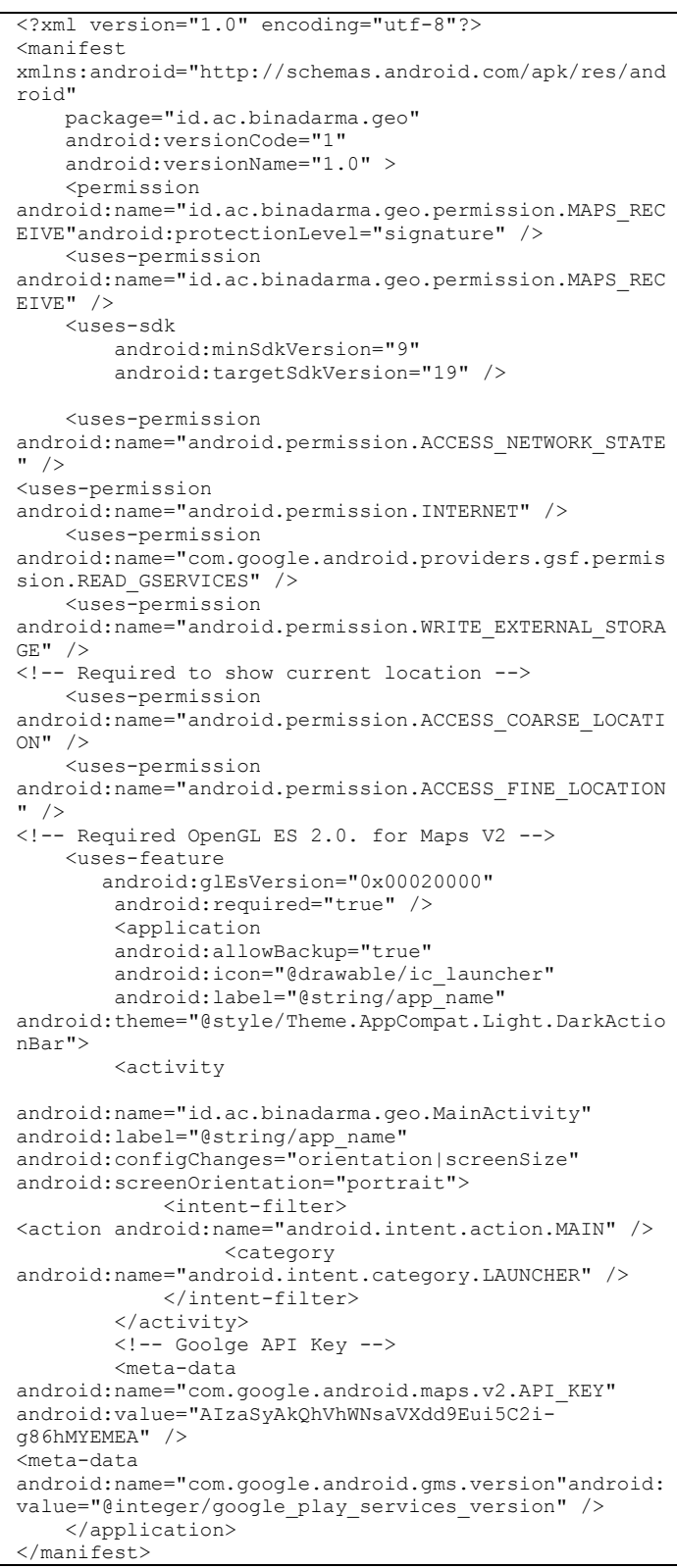

Kode 1. Manifes Program Halte

\section{B. Pembahasan}

1) Implementasi

Hasil implementasi yang dilakukan dalam penelitian ini adalah menghasilkan sebuah aplikasi mobile pencarian halte BRT transmusi Palembang. Pada aplikasi pencarian halte ini menghasilkan informasi berupa peta kota palembang, sebaran halte-halte yang ada di kota palembang, pencarian rute perjalanan berbasis lokasi pengguna, info aplikasi mobile pencarian halte BRT Transmusi Palembang dan tentang pembuat aplikasi.

Implementasi ini juga dilakukan menggunakan android dan web services. Web services digunakan untuk menampung data titiktitik halte yang ada di Kota Palembang dari database ke aplikasi. Penggunaan web service ini untuk memudahkan penambahan titik halte nantinya. Pada Gambar 6 berikut ini dapat dilihat 
arsitektur dari aplikasi mobile pencarian halte BRT Transmusi Palembang.

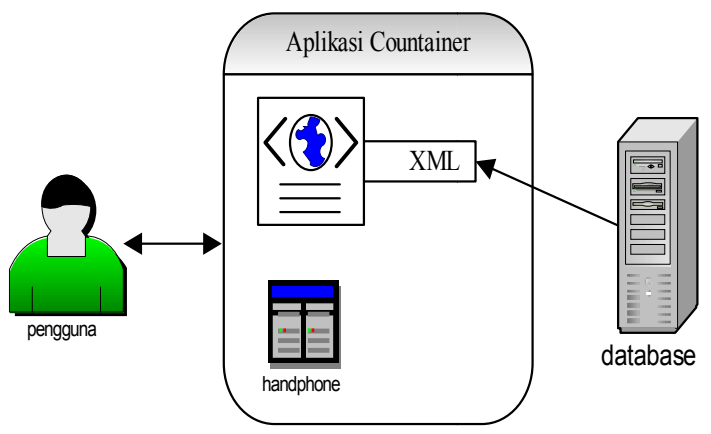

Gambar 6. Arsitektur Aplikasi

Dari arsitektur pada Gambar 6 diatas yang menggambarkan komunikasi pengguna dan aplikasi maka selanjutnya pengguna dapat melihat informasi yang tersedia pada aplikasi mobile pencarian halte BRT Transmusi Palembang yaitu sebagai berikut:

\section{a) Halaman Utama}

Halaman utama adalah halaman pertama kali yang diakses oleh pengguna aplikasi. Pada halaman utama berisikan peta dan logo kota palembang. Pada Gambar 7 terlihat halaman utama dari aplikasi mobile pencarian halte BRT transmusi Palembang.

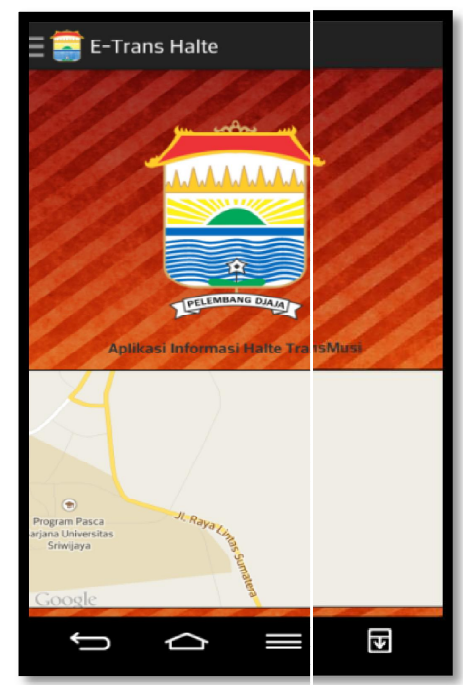

Gambar 7. Halaman Utama

\section{b) Halaman Sebaran Halte}

Halaman sebaran halte halaman yang berisikan informasi sebaran halte yang ada di Kota Palembang. Semua halte yang ada pada halaman ini dimasukkan oleh pengembang dan diakses melalui web services. Pada Gambar 8 berikut adalah tampilan halaman sebaran halte.

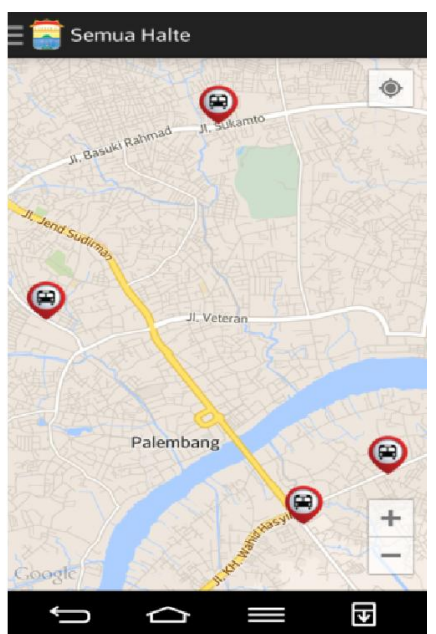

Gambar 8. Halaman Sebaran Halte

\section{c) Halaman Rute Halte}

Halaman rute halte merupakan halaman yang digunakan untuk menampilkan rute perjalanan berdasarkan lokasi pengguna dan ke tujuan yang dipilih. Pada halaman ini pengguna dapat melihat arah perjalanan yang akan ditempuh. Rute perjalanan tersebut dibuat berdasarkan titik GPS pengguna aplikasi mobile pencarian halte BRT transmusi Palembang. Pada Gambar 9 berikut telihat tampilan hasil pencarian rute perjalanan.

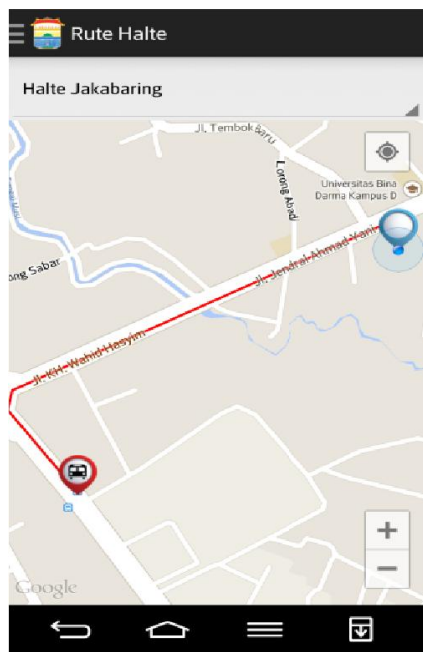

Gambar 9. Halaman Rute Halte

\section{2) Validasi}

Validasi yang dilakukan dalam penelitian pengembangan aplikasi mobile pencarian halte BRT transmusi Palembang ini adalah pengujian tahap akhir sebelum aplikasi mobile pencarian halte BRT transmusi Palembang di launching ke pengguna. Validasi dilakukan dengan melakukan pengujian, Pengujian tersebut dilakukan menggunakan metode black box testing. Hasil pengujian tersebut menunjukkan semua fungsional 
aplikasi berjalan sesuai yang dibutuhkan seperti yang diperlihatkan pada Tabel 1 dan 2.

Tabel 1. Pengujian Sebaran Halte

\begin{tabular}{|l|l|}
\hline \multicolumn{2}{|c|}{ Kasus dan Hasil Ujicoba } \\
\hline Menampilkan Sebaran Halte \\
\hline Data masukan & $\begin{array}{l}\text { Melakukan akses ke menu sebaran } \\
\text { halte yang ada di halaman utama }\end{array}$ \\
\hline Yang diharapkan & $\begin{array}{l}\text { Terjadi proses penampilan dan } \\
\text { sebaran halte dapat dilihat }\end{array}$ \\
\hline Pengamatan & $\begin{array}{l}\text { Sebaran halte dapat ditampilkan } \\
\text { sesuai harapan }\end{array}$ \\
\hline Kesimpulan & {$[\checkmark$ ] Diterima [ ] Ditolak } \\
\hline
\end{tabular}

Tabel 2. Pengujian Rute Halte

\begin{tabular}{|l|l|}
\hline \multicolumn{2}{|c|}{ Kasus dan Hasil Ujicoba } \\
\hline Menampilkan Rute Halte \\
\hline Data masukan & $\begin{array}{l}\text { Memilih halte tujuan berdasarkan } \\
\text { lokasi sekarang }\end{array}$ \\
\hline Yang diharapkan & $\begin{array}{l}\text { dapat menampilkan rute perjalanan } \\
\text { berdasarkan lokasi }\end{array}$ \\
\hline Pengamatan & $\begin{array}{l}\text { Rute perjalanan dapat dilihat } \\
\text { berdasarkan lokasi sekarang }\end{array}$ \\
\hline Kesimpulan & {$[\checkmark]$ Diterima [ ] Ditolak } \\
\hline
\end{tabular}

\section{KESIMPULAN}

Aplikasi Mobile Pencarian Halte BRT Transmusi Palembang telah dikembangkan dengan metode Evolutionary Development yang berbasis object oriented programming.
Berdasarkan uji coba fungsionalitas Aplikasi Mobile Pencarian Halte BRT Transmusi Palembang dapat menunjukan sebaran halte Transmusi yang ada di Kota Palembang sesuai dengan kebutuhan yang ditunjukkan pada fase pengkodean. Selain itu Aplikasi Mobile Pencarian Halte BRT Transmusi Palembang dapat memberikan informasi rute perjalanan melalui halte Transmusi.

\section{DAFTAR PUSTAKA}

Aljufri, F. (2012). Sistem Pemandu Pencarian Masjid Terdekat Berbasis Lokasi Di Atas Platform Android. Yogyakarta: (Doctoral dissertation, UIN SUNAN KALIJAGA).

Pressman, R. (2010). Software engineering: a practitioner's approach. New York: McGrowHill .

Rompas, B. R., Sinsuw, A. A., Sompie, S. R., \& Lumenta, A. S. (2012). Aplikasi Location-based Service Pencarian Tempat di Kota Manado Berbasis Android. Jurnal Teknik Elektro dan Komputer , 1 (2), 1-11.

Sommerville, I. (2011). Software Engineering. Boston: Addison-Wesley.

Sukmadinata, S. N. (2006). Metode Penelitian Pendidikan. Bandung: Remaja Rosdakarya.

Umar, H. (2003). Metode Riset Bisnis. Jakarta: Gramedia Pustaka Utama. 